\title{
Muscarinic acetylcholine receptor activation prevents disinhibition-mediated LTP in the hippocampus
}

\author{
Petri Takkala and Melanie A. Woodin* \\ Department of Cell and Systems Biology, University of Toronto, Toronto, ON, Canada
}

\section{Edited by:}

Arianna Maffei, SUNY Stony Brook, USA

\section{Reviewed by:}

Arianna Maffei, SUNY Stony Brook, USA

Julie S. Haas, Harvard University, USA

\section{${ }^{*}$ Correspondence:}

Melanie A. Woodin, Department of Cell and Systems Biology, University of Toronto, 25 Harbord Street, Toronto, ON M5S 3G5, Canada. e-mail:m.woodin@utoronto.ca
Disinhibition-mediated long-term potentiation (LTP) in the CA1 region of the hippocampus involves GABAergic synaptic plasticity at feedforward inhibitory inputs, resulting in the reduced shunting of glutamatergic excitatory currents. The GABAergic plasticity which underlies disinhibition-mediated LTP results from a $\mathrm{Ca}^{2+}$-dependent decrease in the activity of the $\mathrm{K}^{+}-\mathrm{Cl}^{-}$cotransporter (KCC2), depolarizing the reversal potential for $G_{A B A}$ receptor-mediated currents $\left(E_{G A B A}\right)$, thereby attenuating inhibition. Muscarinic acetylcholine receptor (mAChR) activation has previously been shown to regulate classic glutamatergic LTP, modulate intracellular $\left[\mathrm{Ca}^{2+}\right.$ ] and signaling, and facilitate the excitability of GABAergic interneurons in the CA1. Based on these effects, and the ability of mAChR activation to regulate CA1 pyramidal neuron KCC2 expression, we proposed that $\mathrm{mAChR}$ activation would modulate disinhibition-mediated LTP. To test this prediction, we made whole cell recordings from CA1 pyramidal neurons in hippocampal slices. Disinhibition-mediated LTP was induced using a spike timing-dependent plasticity (STDP) protocol, which involved coincident pre-synaptic stimulation and post-synaptic current injection (at $5 \mathrm{~Hz}$ for $60 \mathrm{~s}$ ). We found that $\mathrm{mAChR}$ activation via carbachol (CCh) prevented the induction of disinhibition-mediated LTP. Moreover, in the presence of CCh, $\mathrm{E}_{\mathrm{GABA}}$ failed to depolarize following plasticity induction. Lastly, we recorded the paired-pulse ratio (PPR) during the induction of disinhibition-mediated LTP and found that in the presence of $\mathrm{CCh}$, plasticity induction induced a significant paired-pulse depression. This suggests that pre-synaptic mAChR activation may prevent the post-synaptic expression of disinhibition-mediated LTP.

Keywords: acetylcholine, neuromodulation, STDP, LTP, IPSP, hippocampus, CA1, disinhibition

\section{INTRODUCTION}

Long-term potentiation (LTP) is mostly studied at glutamatergic synapses onto pyramidal neurons, and is the leading cellular model of learning and memory (Malinow et al., 2000; Malenka, 2003; Lynch, 2004). This classic glutamatergic LTP depends on NMDA receptor activation, and results from AMPA receptor phosphorylation and an increase in their post-synaptic membrane expression. A novel form of LTP in the hippocampus, termed disinhibition-mediated LTP, which results from the synaptic plasticity of inhibitory GABAergic synapses has recently been demonstrated (Ormond and Woodin, 2009, 2011). When coincident pre- and post-synaptic activity induce inhibitory GABAergic plasticity at feedforward inhibitory inputs (Woodin et al., 2003), the net result is a reduced shunting of excitatory currents onto pyramidal neurons. The effect of disinhibitionmediated LTP is a long-term, synapse-specific (Ormond and Woodin, 2011) increase in the amplitude of Schaffer collateralmediated post-synaptic potentials (PSPs).

During learning and memory processing, neuronal circuits in the hippocampus are modified by neuromodulators that regulate synaptic plasticity (Parent and Baxter, 2004; Giocomo and Hasselmo, 2007). How these neuromodulators regulate disinhibition-mediated LTP, and in turn how disinhibition-mediated LTP regulates the output of the hippocampus is not known. The objective of the present study was to determine the role of cholinergic neuromodulation in disinhibition-mediated LTP.

Hippocampal function is modulated by endogenous acetylcholine (ACh), which is released primarily from cholinergic fibers from the medial septum. Lesion of the medial septum removes the hippocampal cholinergic innervation and induces pronounced memory defects (Hagan et al., 1988; Giocomo and Hasselmo, 2007). It is also well-known that degeneration of the medial septum contributes to the cognitive deficits of Alzheimer's disease (Terry and Buccafusco, 2003). The neuromodulatory effects of ACh have also been well-documented in non-diseased human and animal behavioral experiments which show that in vivo administration of the muscarinic antagonist scopolamine prevents memory encoding (Ghoneim and Mewaldt, 1975; Giocomo and Hasselmo, 2007). Taken together, these studies have led in part to the prevailing idea that cholinergic modulation is essential for memory encoding in the hippocampus (Hasselmo and Giocomo, 2006).

In vitro hippocampal slice studies have also demonstrated a pronounced role for ACh in synaptic plasticity [the cellular basis of memory encoding (Morris et al., 2003)]. ACh acts on 
metabotropic muscarinic acetylcholine receptor (mAChRs) and ionotropic nicotinic $\mathrm{ACh}$ receptors (nAChRs) to produce a variety of neuromodulatory effects in the hippocampus (Giocomo and Hasselmo, 2007). mAChR agonists facilitate the induction of classic glutamatergic LTP in the hippocampus (Burgard and Sarvey, 1990; Huerta and Lisman, 1993; Auerbach and Segal, 1996; Shimoshige et al., 1997; Shinoe et al., 2005), however, a central mechanism underlying this enhancement has not emerged. $\mathrm{ACh}$ agonists and mAChR activation have profound effects on GABAergic interneurons in the CA1: they depolarize their membrane potentials (Chapman and Lacaille, 1999), increase their spiking activity (Pitler and Alger, 1992), and increase inhibitory post-synaptic current (IPSC) frequency (Pitler and Alger, 1992). Moreover, there are also neuromodulatory cholinergic effects on CA1 pyramidal neurons: $\mathrm{mAChR}$ activation increases pyramidal neuron excitability (Markram and Segal, 1990a,b; Huerta and Lisman, 1993; Rosato-Siri et al., 2006), and causes their depolarization (Cole and Nicoll, 1984; Widmer et al., 2006); while muscarinic receptor agonists enhance NMDA currents (Markram and Segal, 1990b), and reduce the $\mathrm{Ca}^{2+}$-dependent $\mathrm{K}^{+}$-channel current and $\mathrm{M}$-currents that contribute to pyramidal neuron adaptation. Taken together, the effects of ACh on both interneurons and pyramidal neurons are to enhance neuronal excitability (by depolarizing the membrane potential toward action potential threshold) and to strengthen inhibition, as seen by increases in IPSC frequency. These ACh-induced modifications of neuronal properties, coupled with the effects of ACh on synaptic transmission and plasticity, have led us to hypothesize that mAChRactivation enhances the induction of disinhibition-mediated LTP. We tested this hypothesis by making whole-cell recordings from pyramidal neurons in the CA1 region of the hippocampus.

\section{MATERIALS AND METHODS HIPPOCAMPAL SLICE PREPARATION}

All experiments were conducted using brain tissue from 14 to 40 days old male C57BL/6 mice housed under standard conditions in a $12 \mathrm{~h} \mathrm{light/dark} \mathrm{cycle.} \mathrm{Mice} \mathrm{were} \mathrm{housed} \mathrm{with} \mathrm{male} \mathrm{litter-}$ mates and provided food and water ad libitum. Prior to dissection, one mouse was isolated from its littermates and anesthetized using isoflurane (Halocarbon Products Corporation, River Edge, NJ, USA), followed by decapitation and rapid removable of the brain, which was then placed into chilled modified artificial cerebral spinal fluid (aCSF). This modified aCSF consisted of (mM) sucrose (216), $\mathrm{KCl}$ (2.5), $\mathrm{NaH}_{2} \mathrm{PO}_{4}$ (1.25), $\mathrm{NaHCO}_{3}$ (25), glucose (25), ascorbic acid (0.4), $\mathrm{CaCl}_{2}(1), \mathrm{MgCl}_{2}$ (2), and sodium pyruvate (3), in double distilled water (Millipore Corporation, Billerica, MA, USA); $\mathrm{pH}=7.4$, osmolality $=300 \mathrm{mOsm} / \mathrm{kg}$. After $1 \mathrm{~min}$ in chilled modified aCSF, the brain was placed onto filter paper, on which the rostral $1 / 3$ of the brain, corresponding approximately to the forebrain anterior of the corpus callosum, and the cerebellum were removed using a sterile surgical blade (Feather, Kita-ku, Osaka, JP). The remaining tissue portion was secured to a vibratome chuck by its ventral surface, and stabilized with a $4 \%$ agar block set to abut the caudal surface of the brain. Both the tissue and agar block were submerged in chilled modified aCSF bubbled with carbogen $\left(95 \% \mathrm{O}_{2} / 5 \% \mathrm{CO}_{2}\right)$. The chuck was surrounded with ice for the duration of the slicing process.
Horizontal slices were cut using a Vibratome 1000 Plus tissue sectioning system (Vibratome Company, St. Louis, MO, USA). Slices were made to a thickness of $375 \mu \mathrm{m}$. Slices were maintained in an interface chamber for at least $60 \mathrm{~min}$ at room temperature, in which Earle's Balanced Salt Solution (EBSS) (Gibco-Life Technologies, Grand Island, NY, USA) was supplemented with $(\mathrm{mM}) \mathrm{CaCl}_{2}$ (1) and $\mathrm{MgCl}_{2}$ (3), and bubbled with $95 \% \mathrm{O}_{2} / 5 \%$ $\mathrm{CO}_{2}$ carbogen. Experiments were conducted with tissue maintained in aCSF which consisted of (mM) NaCl (125), $\mathrm{KCl}(2.5)$, $\mathrm{NaH}_{2} \mathrm{PO}_{4}$ (1.25), $\mathrm{NaHCO}_{3}$ (25), glucose (25), $\mathrm{CaCl}_{2}$ (2), and $\mathrm{MgCl}_{2}$ (1), in double distilled water (Millipore Corporation, Billerica, MA, USA); $\mathrm{pH}=7.4$, osmolality $=300 \mathrm{mOsm} / \mathrm{kg}$. This aCSF was bubbled with $95 \% \mathrm{O}_{2} / 5 \% \mathrm{CO}_{2}$ carbogen and maintained at $38^{\circ} \mathrm{C}$ prior to each experiment. Brain slices were longitudinally cut into hemisections; one hemisection was submerged and anchored in a slice chamber during each recording.

All experiments were performed in accordance with procedures outlined by the Canadian Council of Animal Care, and were approved by the University of Toronto Animal Care Committee.

\section{ELECTROPHYSIOLOGY}

Experiments were performed using an Olympus BX51WI upright microscope (Olympus Canada Inc., Richmond Hill, ON, Canada). Whole-cell patch clamp recordings were made from putatively identified CA1 pyramidal neurons in aCSF flowing at $2 \mathrm{ml} / \mathrm{min}$. Bath aCSF perfusion temperature was monitored and maintained at $37.4^{\circ} \mathrm{C}$ using an in-line solution heater (Warner Instruments, Hamden, CT, USA) controlled by a TC-344B Dual Automatic Temperature Controller (Warner Instruments, Hamden, CT, USA). Micropipettes were made from thin-walled borosilicate glass capillaries (TW-150F; World Precision Instruments Inc., Sarasota, FL, USA) to a resistance of 4-6 M $\Omega$ using a P-87 Flaming/Brown micropipette puller (Sutter Instrument Co., Novato, CA, USA). Micropipettes, containing a $\mathrm{Ag} / \mathrm{AgCl}$ electrode, were filled with $(\mathrm{mM})$ potassium gluconate (130), KCl (10), HEPES (10), EGTA (0.2), ATP (4), GTP (0.3), phosphocreatine (10); $\mathrm{pH}=7.4$, osmolality $=300 \mathrm{mOsm} / \mathrm{kg}$. Signals were recorded using a Digidata 1322A Data Acquisition System, and Multiclamp 700B Microelectrode Amplifier controlled with Multiclamp 700B Commander software and pClamp 9.2 software (Axon Instruments Inc., Union City, CA, USA). Signal sampling was done at $200 \mu$ s intervals, and was low-pass filtered to $10 \mathrm{kHz}$. The seal leak current $\left(\mathrm{I}_{\text {leak }}\right)$ was monitored throughout each experiment; patch-clamp recordings were abandoned if the $\mathrm{I}_{\text {leak }}$ exceeded $100 \mathrm{pA}$.

Extracellular stimulation of Schaffer collateral axons was applied through a micropipette containing a $\mathrm{Ag} / \mathrm{AgCl}$ wire and filled with aCSF. This micropipette stimulating electrode was positioned within the stratum radiatum between the CA3 and CA1 subregions of the hippocampus, at a depth of approximately $2-3$ cell layers in order to stimulate Schaffer collateral axons upon command.

Stimulus intensity was controlled using an A.M.P.I. ISO-FLEX stimulus isolator (IBIS Instrumentation Canada Inc., Ottawa, ON, CA), whereas stimulus duration and frequency were controlled using Multiclamp 700B Commander software and pClamp 9.2 software (Axon Instruments Inc., Union City, CA, USA). 


\section{MEASUREMENT OF $\mathrm{E}_{\mathrm{GABA}}$ AND $\mathrm{E}_{\mathrm{rev}}$}

$\mathrm{E}_{\mathrm{GABA}}$ recordings were performed in the presence of CNQX $(10 \mu \mathrm{M})$ to block AMPA-mediated synaptic transmission. PSPs were evoked through the extracellular stimulation of interneurons during a post-synaptic current clamp step protocol. Current clamp steps ranged from -100 to $50 \mathrm{pA}$, with a $25 \mathrm{pA}$ step interval, and were applied for $600 \mathrm{~ms}$ while recordings were low-pass filtered at $10 \mathrm{kHz}$. Two hundred microseconds after the current clamp step was initiated, a $150 \mu \mathrm{A}, 2$ ms extracellular stimulus was triggered. The PSP amplitude was recorded at each current step and was plotted relative to the preceding membrane potential. This data was used to generate PSP-membrane potential plots; a simple linear regression of these plots was then used to determine $\mathrm{E}_{\mathrm{GABA}}$, which was taken as the intercept of this line with the abscissa. $\mathrm{E}_{\mathrm{rev}}$ is the reversal potential of mixed PSPs comprised of a summated EPSP and IPSP. Thus, $\mathrm{E}_{\text {rev }}$ was determined in the same manner as $\mathrm{E}_{\mathrm{GABA}}$, however, $\mathrm{AMPA}$ receptors were not antagonized.

\section{PLASTICITY INDUCTION}

Disinhibition-mediated LTP was induced in current clamp mode by pairing extracellular stimulation of pre-synaptic inputs with post-synaptic current injection ( $1 \mathrm{nA}$ for $10 \mathrm{~ms}$ ) at a frequency of $5 \mathrm{~Hz}$ for $1 \mathrm{~min}$, as previously described (Ormond and Woodin, 2009, 2011). During this plasticity induction protocol the postsynaptic neuron normally fired two action potentials per pairing. The delay between pre-synaptic stimulation and post-synaptic spiking was $5-10 \mathrm{~ms}$.

\section{PLASTICITY ANALYSIS}

Plasticity expression was measured as a change in the magnitude of PSPs in CA1 pyramidal neurons in response to orthodromic Schaffer collateral stimulation. Disinhibition-mediated LTP was taken to consist of an increase in the PSP amplitude as well as a depolarization of $\mathrm{E}_{\mathrm{rev}}$, as reported previously (Ormond and Woodin, 2009, 2011). However, mAChR-activation has been reported to depolarize pyramidal neurons (Markram and Segal, 1990a,b; Huerta and Lisman, 1993), which we also consistently observed (data not shown). Due to the depolarization of the resting membrane potential (RMP) during CCh application, we could not plot the absolute PSP amplitude. The magnitude of the PSP amplitude results from the synaptic conductance and the driving force (DF) through synaptic receptors. The DF was taken to be the difference between the RMP and $\mathrm{E}_{\text {rev }}$. The PSP amplitude was divided by the DF, and normalized to the average of the baseline value from the 5 min preceding plasticity induction.

\section{CALCULATION OF THE PPR}

The paired-pulse ratio (PPR) was recorded by stimulating two PSPs with a $180 \mathrm{~ms}$ inter-pulse interval, repeated at $0.05 \mathrm{~Hz}$ for $5 \mathrm{~min}$. The PPR was then calculated as the ratio of the second PSP amplitude to the first PSP amplitude $\left(\mathrm{PSP}=\mathrm{PSP}_{2} / \mathrm{PSP}_{1}\right)$.

\section{CHEMICALS}

6-cyano-7-nitroquinoxaline-2,3-dione (CNQX) and carbachol (CCh) were purchased from Sigma-Aldrich (Sigma-Aldrich Co., St. Louis, MO, USA).

\section{DATA ANALYSIS AND STATISTICS}

Data were acquired using Axon Instruments Clampex 9 software, and analyzed using Axon Instruments Clampfit (Axon Instruments Inc., Union City, CA, USA). Results are expressed as mean \pm standard error of the mean (SEM). All statistical tests were performed in SigmaStat (Systat Software, San Jose, CA, USA). Statistical analyses were performed using the following tests: Figure 1D, Student's $t$-test; Figures 2A,B, TwoWay ANOVA followed by Student's $t$-test; Figures 2C,D, Student's $t$-test; Figure 3C, Two-Way ANOVA, Figure 3D, Student's $t$-test.

\section{RESULTS \\ mAChR ACTIVATION DOES NOT REGULATE E $\mathrm{GABA}$}

Our main objective was to determine whether $\mathrm{mAChR}$ activation modulates disinhibition-mediated LTP in the CA1 region of the hippocampus. However, because the mechanism underlying disinhibition-mediated LTP is a depolarization of the reversal potential for PSPs $\left(\mathrm{E}_{\mathrm{rev}}\right)$, which results from a depolarization of the reversal potential for inhibitory $\mathrm{GABA}_{\mathrm{A}}$ receptor-mediated currents $\left(\mathrm{E}_{\mathrm{GABA}}\right)$ (Woodin et al., 2003; Ormond and Woodin, 2009, 2011; Lamsa et al., 2010), we first had to determine whether $\mathrm{mAChR}$ activation alone (prior to plasticity induction) modulates $\mathrm{E}_{\mathrm{GABA}}$. This was especially important in light of a recent report demonstrating that prolonged $\mathrm{mAChR}$ activation promotes KCC2 degradation (Lee et al., 2010), which could presumably depolarize $\mathrm{E}_{\mathrm{GABA}}$.

To determine whether $\mathrm{mAChR}$ activation regulates $\mathrm{E}_{\mathrm{GABA}}$, we stimulated GABA release from interneurons close to the CA1 stratum pyramidale while recording $\mathrm{GABA}_{\mathrm{A}}$ receptor currents in putatively identified CA1 pyramidal neurons. $\mathrm{GABA}_{\mathrm{A}}$ currents were isolated by pharmacologically inhibiting AMPA receptors with CNQX $(10 \mu \mathrm{M})$; NMDA receptors were not inhibited because they are required for the induction of disinhibitionmediated LTP. GABA $\mathrm{A}$ receptor currents were evoked during depolarizing current steps (Figures 1A,B), and the current amplitude was plotted against the membrane potential; the intercept of this curve with the abscissa was taken as $\mathrm{E}_{\mathrm{GABA}}$ (Figure 1C). In standard aCSF (control), the mean $\mathrm{E}_{\mathrm{GABA}}$ was $-71.67 \pm$ $3.07 \mathrm{mV}$ ( $n=7$; Figure 1D). When slices were perfused with the $\mathrm{mAChR}$ agonist $(\mathrm{CCh} ; 10 \mu \mathrm{M})$, there was no significant difference in $\mathrm{E}_{\mathrm{GABA}}$ compared to slices perfused with aCSF $(-69.74 \pm$ $4.21 \mathrm{mV} ; n=7 ; p=0.72$, Student's $t$-test; Figure 1D). Thus, $\mathrm{mAChR}$ activation does not acutely regulate $\mathrm{E}_{\mathrm{GABA}}$ in hippocampal neurons.

\section{mAChR ACTIVATION PREVENTS DISINHIBITION-MEDIATED LTP AND THE DEPOLARIZATION OF E}

mAChR activation increases the spiking activity of GABAergic interneurons in the CA1 (Pitler and Alger, 1992), and increases the excitability of pyramidal neurons (Cole and Nicoll, 1984; Markram and Segal, 1990a,b; Huerta and Lisman, 1993). Since disinhibition-mediated LTP is induced by correlated pre- and post-synaptic activity (Ormond and Woodin, 2009), we predicted that the mAChR-mediated increase in interneuron and pyramidal neuron spiking would facilitate plasticity induction. To test this hypothesis we induced disinhibition-mediated LTP in the absence and presence of CCh. Disinhibition-mediated LTP was 
A

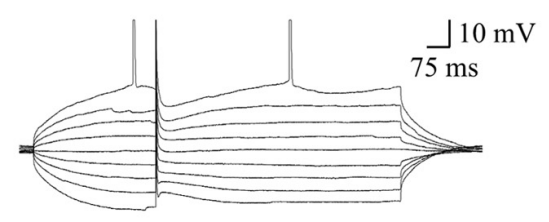

C

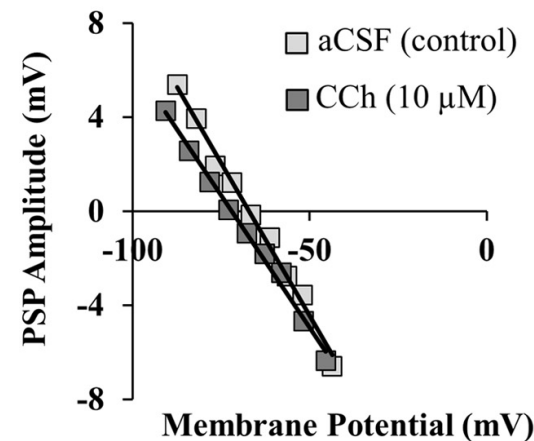

FIGURE 1 | mAChR activation does not alter $\mathbf{E}_{\mathrm{GABA}}$. Sample traces show the current clamp protocol used to record $E_{G A B A}$ after (A) $10 \mathrm{~min}$ of $10 \mu \mathrm{M} \mathrm{CNQX}$, and (B) $10 \mathrm{~min}$ after the addition of $10 \mu \mathrm{M} \mathrm{CCh}$ in the same neuron. The mean resting membrane potential is $-66.29 \pm 0.31 \mathrm{mV}$ in $10 \mu \mathrm{M} \mathrm{CNQX}$, and $-67.67 \pm 0.28 \mathrm{mV}$ with the addition of $10 \mu \mathrm{M}$ CCh. (C) Sample PSP amplitude vs. membrane
B
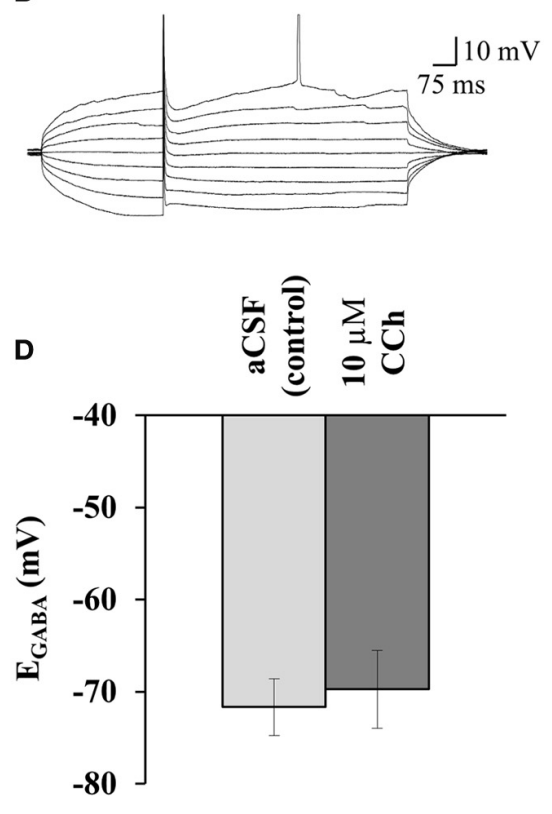

potential plots for a control neuron, and a neuron in $10 \mu \mathrm{M}$ CCh. $\mathrm{E}_{\mathrm{GABA}}$ was recorded in $10 \mu \mathrm{M} \mathrm{CNQX}$, and was taken as the membrane potential where the PSP amplitude was zero (where the linear trend line intersects with the $x$-axis). (D) Summary of all experiments similar to (C). Average $\mathrm{E}_{\mathrm{GABA}}$ for control $(n=7)$ and $\mathrm{CCh}$ perfusion $(n=7)$. Error bars represent \pm one SEM. induced by pairing pre-synaptic stimulation with post-synaptic spiking at $5 \mathrm{~Hz}$ for $1 \mathrm{~min}$. Figure $2 \mathrm{~A}$ shows an example induction of disinhibition-mediated LTP (control; aCSF perfusion); when all experiments similar to this example were summarized there was a significant increase in the PSP amplitude $(p<0.001$, $p$ value is reported for last $5 \mathrm{~min}$ of the recording compared to the 5 min pre-induction baseline, Student's $t$-test; $n=9$ ). However, when these experiments were repeated in the presence of continuous CCh perfusion $(1 \mu \mathrm{M})$, disinhibition-mediated LTP failed to be induced ( $p=0.992 ; n=4)$, as seen in the example trace in Figure 2B. When we compared the recordings from control and CCh experiments we found that there was a significant difference in PSP amplitude (comparing the last $5 \mathrm{~min}$ of each recording (20-25 min bin), $p<0.001$, Student's $t$-test; Figure 2C). Thus, in contrast to our prediction that $\mathrm{mAChR}$ activation would facilitate the induction of disinhibition-mediated LTP, mAChR activation not only failed to facilitate plasticity, it prevented plasticity induction.

As explained above, disinhibition-mediated LTP results from a depolarization of the $\mathrm{E}_{\mathrm{rev}}$. If $\mathrm{mAChR}$ activation prevents plasticity induction, then we should fail to see a depolarization of $\mathrm{E}_{\mathrm{rev}}$ in the presence of $\mathrm{CCh}$, if the plasticity was to be expressed post-synaptically (Ormond and Woodin, 2009, 2011). To test this prediction, we compared the change in the $\mathrm{E}_{\mathrm{rev}}$ at the end of the plasticity experiment to the pre-induction baseline. In the control (aCSF) experiment there was a $4.66 \pm 1.41 \mathrm{mV}$ depolarization in the $\mathrm{E}_{\mathrm{rev}}(n=9 ; p=0.046$, Student's $t$-test $)$; which was consistent with previous findings (Ormond and Woodin, $2009,2011)$. However, in the presence of CCh there was a 3.39 $\pm 0.69 \mathrm{mV}$ hyperpolarization of $\mathrm{E}_{\mathrm{rev}}(n=4 ; p=0.04$, Student's $t$-test). The change in $\mathrm{E}_{\mathrm{rev}}$ between control and $\mathrm{CCh}$ was significant $(p<0.001$, Student's $t$-test; Figure 2D). Thus, mAChR activation prevented disinhibition-mediated LTP by preventing the post-synaptic $\mathrm{E}_{\mathrm{rev}}$ depolarization.

\section{THE mAChR-INDUCED PREVENTION OF DISINHIBITION-MEDIATED LTP IS ACCOMPANIED BY PAIRED-PULSE DEPRESSION}

We next asked whether the mechanism by which $\mathrm{mAChR}$ activation prevents disinhibition-mediated LTP might reside presynaptically. To address this, we recorded the PPR (Figures 3A,B), which is commonly used as a procedure to identify changes in the probability of transmitter release, and thus suggests whether the mechanism of plasticity arises pre- or post-synaptically (Schulz et al., 1994, 1995). The PPR prior to the induction of disinhibition-mediated LTP (in aCSF) was $1.13 \pm 0.09 \mathrm{mV}$ $(n=9$, Figure 3C). Furthermore, the induction of disinhibitionmediated LTP in aCSF did not result in a significant change in the PPR ( $p=0.233$, One-Way ANOVA, $n=9)$, which is consistent with this form of plasticity resulting from a post-synaptic change (Ormond and Woodin, 2009, 2011). During the last $5 \mathrm{~min}$ of the recording, the PPR (in aCSF) was $1.24 \pm 0.06 \mathrm{mV}(n=9)$. When we examined the PPR following plasticity induction in the presence of $1 \mu \mathrm{M} \mathrm{CCh}$, we found that the PPR decreased from 1.27 $\pm 0.04 \mathrm{mV}(n=4)$ before induction, to $0.86 \pm 0.04 \mathrm{mV}(n=4)$ 

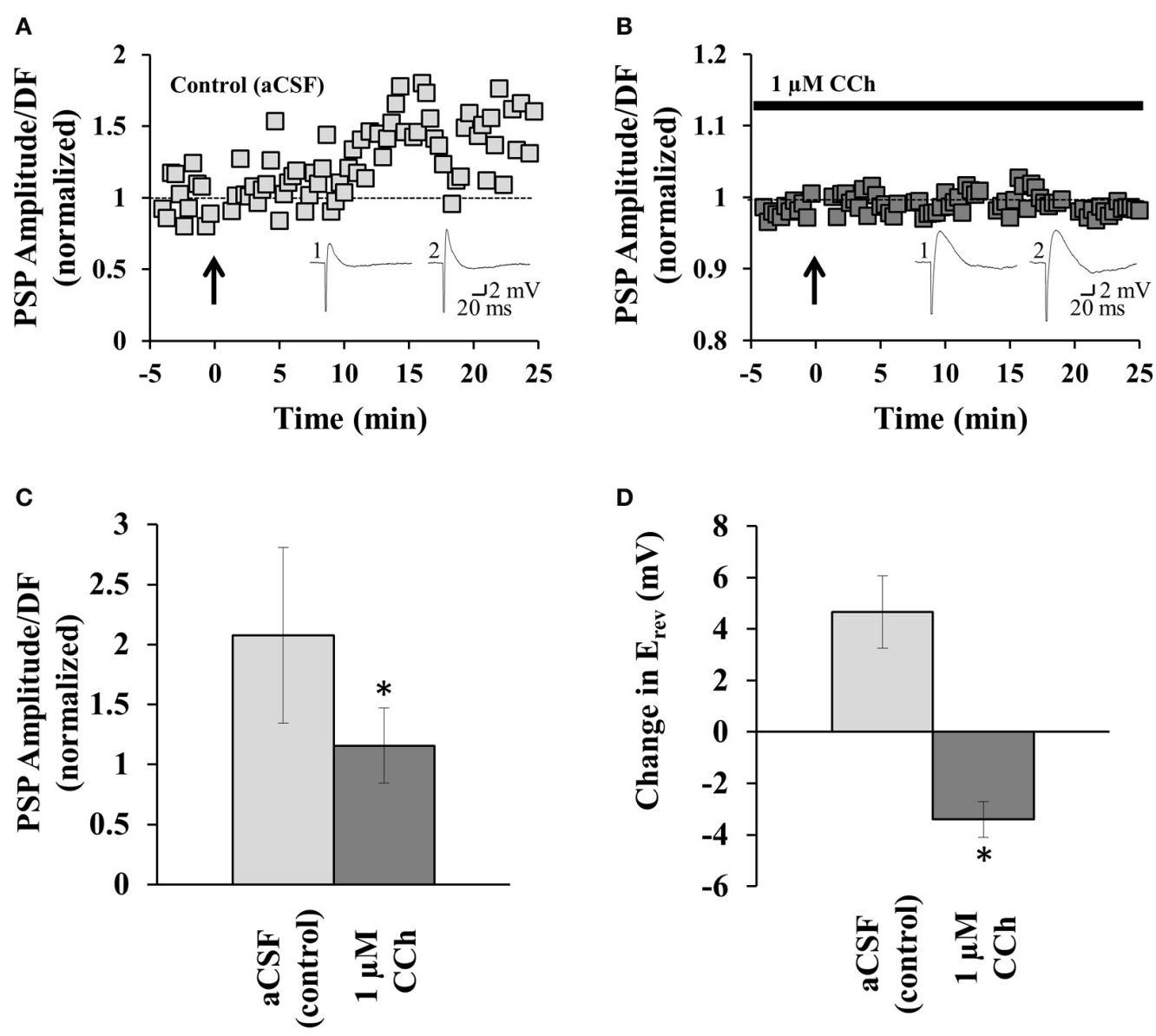

FIGURE 2 | mAChR activation prevents disinhibition-mediated LTP. (A) Example recording from one neuron before and after the induction of disinhibition-mediated LTP (induced at arrow; coincident pre- and post-synaptic activity at $5 \mathrm{~Hz}$ for $1 \mathrm{~min}$ ). PSP amplitude/driving force (DF) values are normalized to the pre-induction baseline (see the Plasticity Analysis section in Experimental Procedures for details on normalization). Insets: sample PSP amplitude recordings before

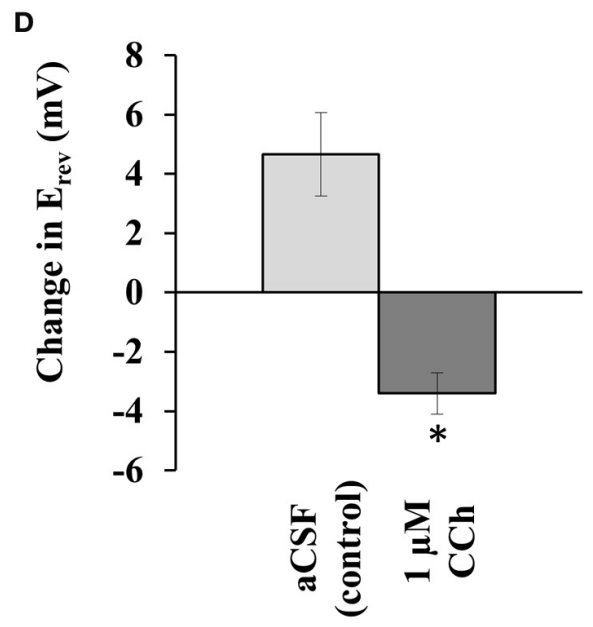

plasticity induction (1), and from the end of the recording period (2). (B) Similar example recording to that in (A), but for a neuron perfused with $1 \mu \mathrm{M}$ CCh. (C) Summary of all experiments similar to those in (A) $(n=9)$ and (B) $(n=4)$. (D) Summary of the change in $E_{\text {rev }}$ for neurons in aCSF or CCh. *indicates significance $(p<0.001)$. Error bars represent \pm one SEM. Dashed lines indicate normalized pre-induction amplitude.

during the last $5 \mathrm{~min}$. The inclusion of CCh lead to a significant depression of the PPR relative to the control experiment ( $p=$ 0.002, Two-Way ANOVA, Figure 3C). Furthermore, the PPR was significantly depressed relative to the control in the final bin of each experiment ( $p<0.001$, Student's $t$-test, Figure 3D). This paired-pulse depression, which began immediately following the plasticity induction protocol, suggests that $\mathrm{mAChR}$ activation acts via a pre-synaptic mechanism to prevent the post-synaptic expression of disinhibition-mediated LTP.

\section{DISCUSSION}

Disinhibition-mediated LTP results from inhibitory synaptic plasticity of feedforward inhibitory inputs onto pyramidal neurons (Ormond and Woodin, 2009, 2011). The mechanism underlying inhibitory synaptic plasticity is a post-synaptic $\mathrm{Ca}^{2+}$ mediated decrease in KCC2 function, which depolarizes $\mathrm{E}_{\mathrm{GABA}}$, essentially weakening synaptic inhibition (Woodin et al., 2003; Saraga et al., 2008; Lamsa et al., 2010). It has previously been shown that $\mathrm{ACh}$, acting on $\mathrm{M}_{1}$ receptors, potentiates $\mathrm{Ca}^{2+}$ transients via G-protein coupled signal transduction, and through second messengers is known to increase the intracellular calcium concentration from intracellular stores (Kirkwood et al., 1991; Gulledge and Stuart, 2005). This suggests that a G-protein coupled mAChR-mediated $\left[\mathrm{Ca}^{2+}\right.$ ] increase can modulate $\mathrm{E}_{\mathrm{GABA}}$ by altering the functional expression of KCC2. There is growing evidence in the literature that neuromodulators may regulate $\mathrm{E}_{\mathrm{GABA}}$. For example, Lee et al. (2010) demonstrated that prolonged activation of mAChRs on cultured hippocampal neurons enhances lysozomal degradation of KCC2, which would presumably depolarize $\mathrm{E}_{\mathrm{GABA}}$. However, in the present study we found that $\mathrm{mAChR}$ activation did not alter $\mathrm{E}_{\mathrm{GABA}}$. The discrepancy in these results likely arises from the high concentration of CCh $(100 \mu \mathrm{M})$ and prolonged use $(120 \mathrm{~min})$ of CCh in the Lee et al. study, compared to the present procedures $(10 \mu \mathrm{M}, 15-30 \mathrm{~min})$.

When disinhibition-mediated LTP was induced in the presence of mAChR activation, we observed a rapid paired-pulse 
A

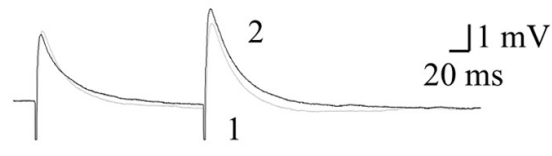

C

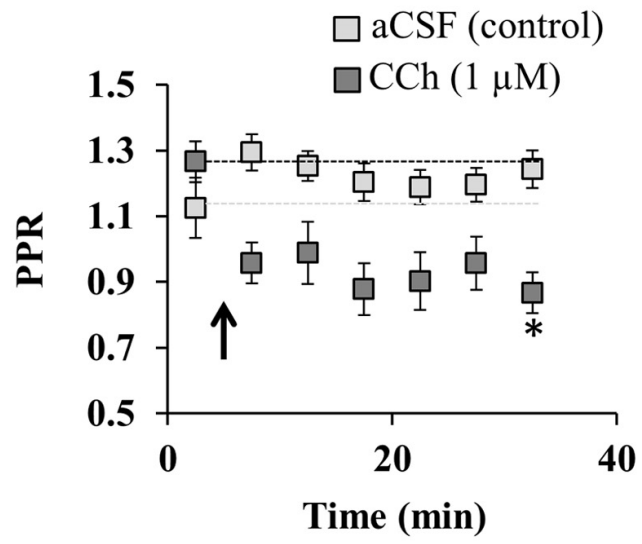

B

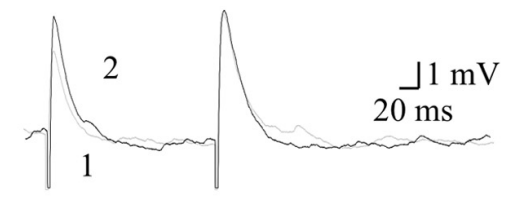

D

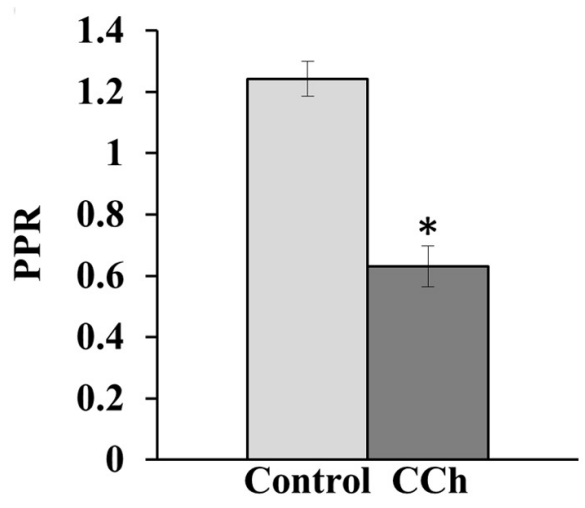

FIGURE 3 | The mAChR-mediated prevention of disinhibition-mediated LTP is accompanied by a decrease in the PPR. Sample traces show the paired-pulse protocol in (A) aCSF and (B) $1 \mu \mathrm{M}$ CCh. Pre-induction recordings of the PPR are shown in gray (1), overlain with post-induction PPR recordings in black (2) from the same neuron. (C) The average PPR before and after the induction of disinhibition-mediated LTP (induced at arrow; coincident pre- and post-synaptic activity at $5 \mathrm{~Hz}$ for $1 \mathrm{~min}$ ), for neurons perfused with aCSF or CCh. ${ }^{*}$ Indicates significance $(p=0.002)$. Dashed lines indicate normalized pre-induction amplitude for each condition. (D) Summary of the PPR ratio in the last $5 \mathrm{~min}$ of the recording for neurons perfused with $\operatorname{aCSF}(n=9)$ or CCh $(n=4)$. *Indicates significance $(p<0.001)$. Error bars represent \pm one SEM. depression immediately following plasticity induction. Shortterm depression is attributed to a decrease in pre-synaptic neurotransmitter release, often due to a depletion of releasable vesicles (Liley and North, 1953; Dobrunz and Stevens, 1997; Bellingham and Walmsley, 1999). If this is the case in our present experiments, it would suggest that despite the ability of mAChR-activation to increase interneuron spiking (Pitler and Alger, 1992), there was a reduction in GABA release which could account for the inability of disinhibition-mediated LTP to be induced. The possible reduction in GABA release could result from a direct action of $\mathrm{mAChR}$ signaling pathways on the release of GABA containing synaptic vesicles. This possibility is supported by the finding that when the $\mathrm{M}_{2} \mathrm{mAChR}$ is knocked-out, there is an increase in the strength of GABAergic inhibition, which accounts for an impairment in the expression of classic glutamatergic LTP (Shimoshige et al., 1997; Seeger et al., 2004). Further investigation into this mechanism should consider whether the potential CCh-induced decrease in GABA release occurs during plasticity induction, and whether $\mathrm{M}_{2}$ receptor activation is sufficient to inhibit the expression of disinhibitionmediated LTP.

Alternatively, paired-pulse depression and the prevention of disinhibition-mediated LTP in the presence of CCh may be due to a $\mathrm{mAChR}$ desensitization; implicating a post-synaptic locus of neuromodulation. Previous studies have demonstrated a desensitization of mAChR-mediated signal transduction by CCh in hippocampal neurons (Lenox et al., 1988; Pontzer and Crews, 1990). Notably, Adams et al. (2004) showed an inhibition of LTP induction by a spike-pairing stimulation at the Schaffer collateral-CA1 synapse, and speculated that the modulatory action of $\mathrm{mAChR}$ activation on LTP at glutamatergic synapses results from receptor desensitization. However, Pontzer and Crews (1990) demonstrated that the CCh-mediated desensitization of mAChR signal transduction in hippocampal neurons effectively occurs only at higher concentrations of the agonist (i.e., 5-30 $\mu \mathrm{M}$ ), beyond the $1 \mu \mathrm{M}$ concentration used in our study.

Further investigation is required in order to determine whether any of these proposed mechanisms underlie the CChmediated prevention of disinhibition-mediated LTP. To this end, it would be prudent to consider the known expression pattern of $\mathrm{mAChR}$ subtypes, and consider their relative affinity to CCh. Notably, $\mathrm{M}_{2}$ receptors on pre-synaptic interneuron terminals have previously been shown to suppress GABA release (Fukudome et al., 2004), and pre-synaptic $\mathrm{M}_{1}$ and $\mathrm{M}_{2}$ have been shown to suppress Schaffer collateral-CA1 synaptic potentials (Kremin et al., 2006). In addition, GABA release suppression by retrograde signaling has also been demonstrated (Ohno-Shosaku et al., 2003), therefore post-synaptic $M_{1}$ and $M_{3}$ receptors may act indirectly to suppress synaptic transmission. A robust pharmacological investigation, paired with the appropriate genetic tools can be used to further investigate the underlying mechanism by which CCh prevents disinhibition-mediated LTP. 
In conclusion, the present study provides the first evidence that disinhibition-mediated LTP is modulated by the cholinergic neuromodulatory system. Specifically, we found that $\mathrm{mAChR}$-activation prevents the induction of disinhibitionmediated LTP in CA1 pyramidal neurons. Disinhibitionmediated LTP is expressed post-synaptically via a depolarization of the $\mathrm{E}_{\mathrm{rev}}$ (Ormond and Woodin, 2009). While mAChRactivation prevented the depolarization of $\mathrm{E}_{\mathrm{rev}}$ post-synaptically, we also observed a paired pulse depression following plasticity induction, which suggests that the mechanism of

\section{REFERENCES}

Adams, S. V., Winterer, J., and Müller, W. (2004). Muscarinic signaling is required for spike-pairing induction of long-term potentiation at rat Schaffer collateral-CA1 synapses. Hippocampus 14, 413-416.

Auerbach, J. M., and Segal, M. (1996). Muscarinic receptors mediating depression and long-term potentiation in rat hippocampus. J. Physiol. 492, 479-493.

Bellingham, M. C., and Walmsley, B. (1999). A novel presynaptic inhibitory mechanism underlies paired pulse depression at a fast central synapse. Neuron 23, 159-170.

Burgard, E. C., and Sarvey, J. M. (1990). Muscarinic receptor activation facilitates the induction of long-term potentiation (LTP) in the rat dentate gyrus. Neurosci. Lett. 116, 34-39.

Chapman, C. A., and Lacaille, J. C. (1999). Cholinergic induction of theta-frequency oscillations in hippocampal inhibitory interneurons and pacing of pyramidal cell firing. J. Neurosci. 19, 8637-8645.

Cole, A. E., and Nicoll, R. A. (1984). Characterization of a slow cholinergic post-synaptic potential recorded in vitro from rat hippocampal pyramidal cells. J. Physiol. 352, 173-188.

Dobrunz, L. E., and Stevens, C. F. (1997). Heterogeneity of release probability, facilitation, and depletion at central synapses. Neuron 18 , 995-1008.

Fukudome, Y., Ohno-Shosaku, T., Matsui, M., Omori, Y., Fukaya, M., Tsubokawa, H., et al. (2004). Two distinct classes of muscarinic action on hippocampal inhibitory synapses: M2-mediated direct suppression and M1/M3-mediated indirect suppression through endocannabinoid signaling. Eur. J. Neurosci. 19, 2682-2692.

Ghoneim, M. M., and Mewaldt, S. P. (1975). Effects of diazepam and scopolamine on storage, retrieval and organizational processes in memory. Psychopharmacologia 44, 257-262.

Giocomo, L. M., and Hasselmo, M. E. (2007). Neuromodulation by glutamate and acetylcholine can change circuit dynamics by regulating the relative influence of afferent input and excitatory feedback. Mol. Neurobiol. 36, 184-200.

Gulledge, A. T., and Stuart, G. J. (2005). Cholinergic inhibition of neocortical pyramidal neurons. J. Neurosci. 25, 10308-10320.

Hagan, J. J., Salamone, J. D., Simpson, J., Iversen, S. D., and Morris, R. G. (1988). Place navigation in rats is impaired by lesions of medial septum and diagonal band but not nucleus basalis magnocellularis. Behav. Brain Res. 27, 9-20.

Hasselmo, M. E., and Giocomo, L. M. (2006). Cholinergic modulation of cortical function. J. Mol. Neurosci. 30, 133-135.

Huerta, P. T., and Lisman, J. E. (1993). Heightened synaptic plasticity of hippocampal CA1 neurons during a cholinergically induced rhythmic state. Nature 364, 723-725.

Kirkwood, A., Simmons, M. A., Mather, R. J., and Lisman, J. (1991). Muscarinic suppression of the M-current is mediated by a rise in internal $\mathrm{Ca}^{2+}$ concentration. Neuron 6, 1009-1014.

Kremin, T., Gerber, D., Giocomo, L. M., Huang, S. Y., Tonegawa, S., and Hasselmo, M. E. (2006). Muscarinic suppression in stratum radiatum of CA1 shows dependence on presynaptic M1 receptors and is not dependent on effects of GABAB receptors. Neurobiol. Learn. Mem. 85, 153-163.

Lamsa, K., Kullmann, D. M., and Woodin, M. A. (2010). Spike-timing dependent plasticity in inhibitory circuits. Front. Syn. Neurosci. 2:8. doi: 10.3389/fnsyn.2010.00008

Lee, H. H., Jurd, R., and Moss, S. J. (2010). Tyrosine phosphorylation regulates the membrane

prevention may reside pre-synaptically. In addition to providing novel evidence for the neuromodulation of disinhibitionmediated LTP, this is the first study to demonstrate that disinhibition-mediated LTP can be induced in the mouse hippocampus.

\section{ACKNOWLEDGMENTS}

This study was supported by a grant from the Natural Sciences and Engineering Research Council of Canada (NSERC) to Melanie A. Woodin.

trafficking of the potassium chloride co-transporter KCC2. Mol. Cell. Neurosci. 45, 173-179.

Lenox, R. H., Hendley, D., and Ellis, J. (1988). Desensitization of muscarinic receptor-coupled phosphoinositide hydrolysis in rat hippocampus: comparisons with the alpha 1-adrenergic response. J. Neurochem. 50, 558-564.

Liley, A. W., and North, K. A. (1953). An electrical investigation of effects of repetitive stimulation on mammalian neuromuscular junction. J. Neurophysiol. 16, 509-527.

Lynch, M. A. (2004). Long-term potentiation and memory. Physiol. Rev. 84, 87-136.

Malenka, R. C. (2003). The long-term potential of LTP. Nat. Rev. Neurosci. 4, 923-926.

Malinow, R., Mainen, Z. F., and Hayashi, Y. (2000). LTP mechanisms: from silence to four-lane traffic. Curr. Opin. Neurobiol. 10, 352-357.

Markram, H., and Segal, M. (1990a). Acetylcholine potentiates responses to N-methyl-D-aspartate in the rat hippocampus. Neurosci. Lett. 113 , 62-65.

Markram, H., and Segal, M. (1990b). Long-lasting facilitation of excitatory postsynaptic potentials in the rat hippocampus by acetylcholine. J. Physiol. 427, 381-393.

Morris, R. G., Moser, E. I., Riedel, G., Martin, S. J., Sandin, J., Day, M., et al. (2003). Elements of a neurobiological theory of the hippocampus: the role of activity-dependent synaptic plasticity in memory. Philos. Trans. R. Soc. Lond. B Biol. Sci. 358, 773-786.

Ohno-Shosaku, T., Matsui, M., Fukudome, Y., Shosaku, J. Tsobokawa, H., Taketo, M., et al. (2003). Postsynaptic M1 and M3 receptors are responsible for the muscarinic enhancement of retrograde endocannabinoid signaling in the hippocampus. Eur. J. Neurosci. 18, 109-116.

Ormond, J., and Woodin, M. A. (2009). Disinhibition mediates a form of hippocampal long-term potentiation in area CA1. PLOS ONE 4:e7224. doi: 10.1371/journal.pone. 0007224

Ormond, J., and Woodin, M. A. (2011). Disinhibition-mediated LTP in the hippocampus is synapse specific. Front. Cell. Neurosci. 5:17. doi: 10.3389/fncel.2011.00017

Parent, M. B., and Baxter, M. G. (2004). Septohippocampal acetylcholine: involved in but not necessary for learning and memory? Learn. Mem. 11, 9-20.

Pitler, T. A., and Alger, B. E. (1992). Cholinergic excitation of GABAergic interneurons in the rat hippocampal slice. J. Physiol. 450, 127-142.

Pontzer, N. J., and Crews, F. T. (1990). Desensitization of muscarinic stimulated hippocampal cell firing is related to phosphoinositide hydrolysis and inhibited by lithium. J. Pharm. Exp. Ther. 253, 921-929.

Rosato-Siri, M., Cattaneo, A., and Cherubini, E. (2006). Nicotineinduced enhancement of synaptic plasticity at CA3-CA1 synapses requires GABAergic interneurons in adult anti-NGF mice. J. Physiol. 576, 361-377.

Saraga, F., Balena, T., Wolansky, T., Dickson, C. T., and Woodin, M. A. (2008). Inhibitory synaptic plasticity regulates pyramidal neuron spiking in the rodent hippocampus. Neuroscience 155 , 64-75.

Schulz, P. E., Cook, E. P., and Johnston, D. (1994). Changes in paired-pulse facilitation suggest presynaptic involvement in long-term potentiation. J. Neurosci. 14, 5325-5337.

Schulz, P. E., Cook, E. P., and Johnston, D. (1995). Using paired-pulse facilitation to probe the mechanisms 
for long-term potentiation (LTP). J. Physiol. 89, 3-9.

Seeger, T., Fedorova, I., Zheng, F., Miyakawa, T., Koustova, E., Gomeza, J., et al. (2004). $\mathrm{M}_{2}$ muscarinic acetylcholine receptor knock-out mice show deficits in behavioral flexibility, working memory, and hippocampal plasticity. J. Neurosci. 24, 10117-10127.

Shimoshige, Y., Maeda, T., Kaneko, S., Akaike, A., and Satoh, A. (1997). Involvement of $\mathrm{M}_{2}$ receptor in an enhancement of long-term potentiation by carbachol in Schaffer collateral-CA1 synapses of hippocampal slices. Neuroscience 27, 175-180.
Shinoe, T., Matsui, M., Taketo, M. M., and Manabe, T. (2005). Modulation of synaptic plasticity by physiological activation of M1 muscarinic acetylcholine receptors in the mouse hippocampus. J. Neurosci. 25, 11194-11200.

Terry, A. V., and Buccafusco, J. J. (2003). The cholinergic hypothesis of age and Alzheimer's diseaserelated cognitive deficits: recent challenges and their implications for novel drug development. J. Pharmacol. Exp. Ther. 306, 821-827.

Widmer, H., Ferrigan, L., Davies, C. H., and Cobb, S. R. (2006). Evoked slow muscarinic acetylcholinergic synaptic potentials in rat hippocampal interneurons. Hippocampus 16, 617-628.

Woodin, M. A., Ganguly, K., and Poo, M. M. (2003). Coincident pre- and postsynaptic activity modifies GABAergic synapses by postsynaptic changes in $\mathrm{Cl}$ transporter activity. Neuron 39, 807-820.

Conflict of Interest Statement: The authors declare that the research was conducted in the absence of any commercial or financial relationships that could be construed as a potential conflict of interest.
Received: 06 December 2012; accepted: 08 February 2013; published online: 28 February 2013

Citation: Takkala $P$ and Woodin MA (2013) Muscarinic acetylcholine receptor activation prevents disinhibitionmediated LTP in the hippocampus. Front. Cell. Neurosci. 7:16. doi: 10.3389/ fncel.2013.00016

Copyright (c) 2013 Takkala and Woodin. This is an open-access article distributed under the terms of the Creative Commons Attribution License, which permits use, distribution and reproduction in other forums, provided the original authors and source are credited and subject to any copyright notices concerning any third-party graphics etc. 